\title{
Study on user experience of airport rail to air Transfer Mode based on QFD and service design methods
}

\author{
Shan Sun ${ }^{1}$, Dongming $\mathrm{Ma}^{2}$ and Hao Qian ${ }^{1 *}$ \\ ${ }^{1}$ Departments of Mechanical and Electrical Engineering, University of Beijing University of Chemical \\ Technology, 100029, china \\ ${ }^{2}$ Departments of Mechanical and Electrical Engineering, University of Beijing University of Chemical \\ Technology, 100029, china
}

\begin{abstract}
Objective: To further perfect service design of "rail to air transfer" mode at Beijing Daxing Airport, optimize the transfer flow and improve passengers' "door to door" transfer experience. Method: Quality function deployment (QFD) method was introduced into the optimization process of service design. Firstly, the user demand for current "rail to air transfer" mode was collected through questionnaire survey and interview method, followed by analysis and classification using $\mathrm{KJ}$ method, user demand weight was determined via analytic hierarch process (AHP) method, the correlation between user demand and design elements was quantitatively evaluated through QFD method, and house of quality (HOQ) was constructed to complete the transformation from user demand into design elements. In the end, service contact analysis was implemented according to obtained parameters, the suggestions for improvement were proposed and the service optimization blueprint was constructed. Conclusion: Starting from user demand, QFD method was integrated with service design to optimize and innovate the service design of the existing "rail to air transfer" mode at Daxing Airport. This study has provided a new strategy and method for improving transfer service and user experience.
\end{abstract}

\section{Introduction}

With flourishing growth of aviation industry and rail traffic in recent years, some core airport hubs in China have started transiting from single civil aviation traffic into a comprehensive passenger transportation hub integrating civil aviation, road and rail traffic [1]. Adhering to the "people-oriented" concept of transportation is an important origin of force for improving service level and operating efficiency, and integrating transportation resources [2].

Transfer experience is an important index influencing passenger travel quality. Among theories regarding transfer at comprehensive passenger transport hub, few literature have investigated "rail to air transfer" passenger service design and user experience of transfer passengers. To solve this problem, Beijing Daxing International Airport Comprehensive Hub taken as the study object, the "rail to air transfer" mode of Daxing Airport was analyzed based on QFD and combining the service design concept.

QFD is a user-centered design quality improvement method proposed by scholars Mizuno and Akao [3]. QFD transforms user demand into the corresponding technical objective of products and conducts product innovation with satisfying user demand as motivation and technical objective as the tool [4].

As one type of system design, service design covers properties like human, object, behavior, environment, etc.[5].Better service experience is created through system analysis, and values are created for two parties providing and enjoying the services [6], where a series of design methods like KJ method, service blueprint, contact point and user portrayal belong to the category of service design. This research is carried out mainly using two methods: service contact point and service blueprint.

\section{Rail to Air transfer mode analysis of Daxing Airport}

As a comprehensive passenger transportation hub integrating terminal, high-speed railway station and traffic center (GTC), Daxing Airport has realized seamless transfer between air traffic and rail traffic. The aboveground floors 1-5 constitute the terminal, underground first floor serves as rail traffic station hall and transfer hall and underground second floor is rail traffic platform as shown in Fig 1.

*Corresponding author's e-mail: 842906190@qq.com 


\begin{tabular}{|c|c|c|c|}
\hline \multirow{5}{*}{ Terminal } & $5 \mathrm{~F}$ & Catering Layer & \\
\hline & $4 \mathrm{~F}$ & Check-in Hall & Check in/HK MO TW \& International Depart \\
\hline & $3 \mathrm{~F}$ & Domestic Boarding & Check in/Domestic Departures \\
\hline & $2 \mathrm{~F}$ & Domestic Arrivals & \\
\hline & $1 \mathrm{~F}$ & International Arrivals & \\
\hline \multirow{2}{*}{$\begin{array}{l}\text { Interchange } \\
\text { Station }\end{array}$} & B1 & Subway Concourse & $\begin{array}{l}\text { Check in \& Security check } \\
\text { (Domestic Departures) }\end{array}$ \\
\hline & B2 & Subway Platform & Transfer service \\
\hline
\end{tabular}

Figure 1. Regional function division and "rail to air transfer" mode

Passenger transfer experience data were collected through questionnaire survey and interview method. User demands were summarized via KJ method, and then AHP was used to acquire user demand weight. HOQ relation matrix of "rail to air transfer" user demand was established through QFD, thus realizing the transformation from user

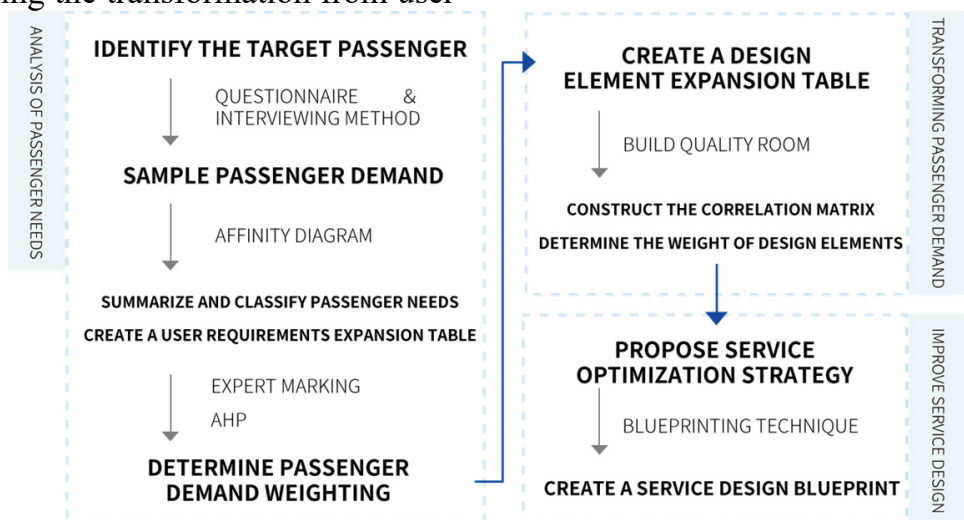

Figure 2. Research flow chart

\section{Research method}

\subsection{Classification of target users and collection of user demands}

In order to make the acquired user demand data more comprehensive, the surveyed target users were classified into general passenger, experienced passenger and special passenger. General passengers are mostly users who basically understand transfer service flow and related operations. Experienced passengers are users who are already familiar with transfer service flow and related operations. Special passengers are users who use transfer demand into design elements. In the end, the suggestions for optimizing "rail to air transfer" service in Daxing Airport were proposed according to HOQ analysis results, and service optimization blueprint was drawn. The research flow is shown in Fig 2.

service the first time, who are physically challenged and who are relatively old.

\subsection{Clustering analysis of passenger demands}

Interview method and questionnaire survey method were used to collect demand information of various users for "rail to air transfer" service. Totally 62 people were interviewed within one week, questionnaire survey was implemented for 200 times, and 178 valid receipts were recovered. A total of 311 user demand information was obtained, and similarity-based division was carried out using KJ method. The obtained grouping results constituted the hierarchical structural chart of "rail to air transfer" service as shown in Fig 3.

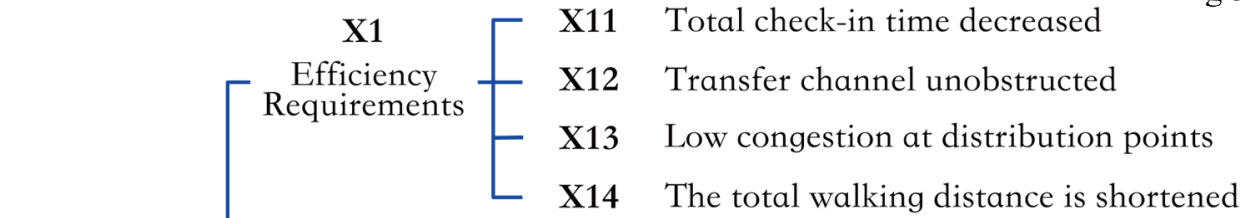

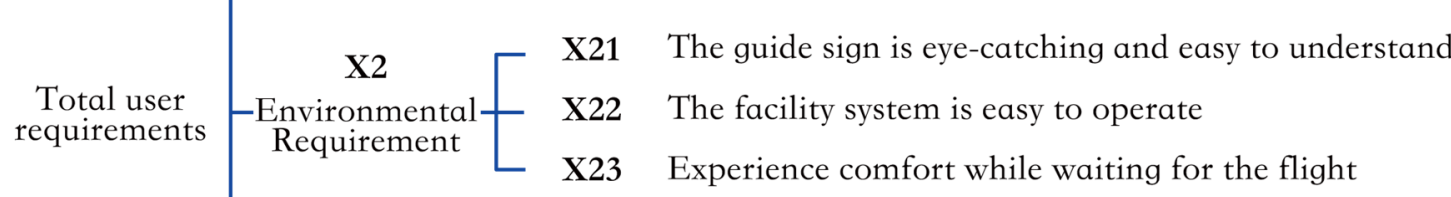

$$
\begin{aligned}
& \begin{array}{c}
\text { X3 } \begin{array}{c}
\text { Service } \\
\text { Requirement }
\end{array}
\end{array}\left[\begin{array}{ll}
\text { X31 } & \text { Better access to smart services } \\
\text { X32 } & \text { Enjoy physical facilities } \\
\text { X33 } & \text { Shorter walking time with luggage }
\end{array}\right.
\end{aligned}
$$

Figure 3. Hierarchical structural chart of user demands 


\subsection{User demand weight analysis}

After the user demand order was determined, the judgment matrix was constructed via AHP method and user demand weight was confirmed [7]. According to unfolding results of user demand in Fig 3, user demands in each order were scored and evaluated by an expert using 1-5 scale division method, and then demand judgment matrix of each order was constituted. The calculation results are seen in Tab 14 , and all results have passed the consistency check.

Table1. Judgment matrix and weight of second-order demand versus first-order total demand

\begin{tabular}{cccccc}
\hline $\begin{array}{c}\text { Second-order } \\
\text { demand }\end{array}$ & $\mathrm{X} 1$ & $\mathrm{X} 2$ & $\mathrm{X} 3$ & $\begin{array}{c}\text { Weight } \\
\text { coefficient } \\
\text { (w) }\end{array}$ & $\begin{array}{c}\text { Consistency } \\
\text { check result }\end{array}$ \\
\hline $\mathrm{X} 1$ & 1 & 3 & 4 & 0.6232 & $\mathrm{CR}=0.018<0$. \\
$\mathrm{X} 2$ & $1 / 3$ & 1 & 2 & 0.2395 & 1 \\
\hline $\mathrm{X} 3$ & $1 / 4$ & $1 / 2$ & 1 & 0.1373 & \\
\hline
\end{tabular}

Table2. Efficiency demand judgment matrix and weight

\begin{tabular}{|c|c|c|c|c|c|}
\hline Third-order demand & $\mathrm{X} 11$ & $\mathrm{X} 12$ & $\mathrm{X} 13$ & $\mathrm{X} 14$ & Consistency check result \\
\hline $\mathrm{X} 11$ & 1 & 3 & $1 / 2$ & 4 & \multirow{4}{*}{$\mathrm{CR}=0.080<0.1$} \\
\hline $\mathrm{X} 12$ & $1 / 3$ & 1 & $1 / 3$ & 3 & \\
\hline $\mathrm{X} 13$ & 2 & 3 & 1 & 3 & \\
\hline $\mathrm{X} 14$ & $1 / 4$ & $1 / 3$ & $1 / 3$ & 1 & \\
\hline
\end{tabular}

Table3. Environmental demand judgment matrix and weight

\begin{tabular}{cccccc}
\hline Third-order demand & X21 & X22 & X23 & Weight coefficient (w) & Consistency check result \\
\cline { 1 - 5 } X21 & 1 & 2 & 4 & 0.5437 & \\
\cline { 1 - 5 } X22 & $1 / 2$ & 1 & 4 & 0.3460 & CR $=0.052<0.1$ \\
\cline { 1 - 5 } X23 & $1 / 4$ & $1 / 4$ & 1 & 0.1103 & \\
\hline
\end{tabular}

Table4. Service demand judgment matrix and weight

\begin{tabular}{cccccc}
\hline Third-order demand & X31 & X32 & X33 & Weight coefficient (w) & Consistency check result \\
\hline X31 & 1 & 3 & 2 & 0.5389 & \\
\cline { 1 - 5 } X32 & $1 / 3$ & 1 & $1 / 2$ & 0.1638 & CR $=0.009<0.1$ \\
X33 & $1 / 2$ & 2 & 1 & 0.2973 & \\
\hline
\end{tabular}

Weight calculation of third-order demand versus firstorder demand was carried out for weight values in the above tables, and then user demand weights of "rail to air

Table5. Transfer user demand weight

\begin{tabular}{ccccccccccc}
\hline $\begin{array}{c}\text { Third-order } \\
\text { demand }\end{array}$ & X11 & X12 & X13 & X14 & X21 & X22 & X23 & X31 & X32 & X33 \\
\hline Total weight & 0. & 0. & 0. & 0. & 0. & 0. & 0. & 0. & 0. & 0. \\
& 1998 & 1022 & 2651 & 0561 & 1302 & 0829 & 0264 & 0740 & 0225 & 0408 \\
\hline
\end{tabular}

transfer" service of Daxing Airport were acquired (as shown in Tab 5).

\subsection{Establishment of QFD model and HOQ relation matrix}

Abstract user demand should be transformed into concrete design elements for the sake of product optimization and innovation [8]. Design element is namely ceiling part in HOQ. According to the characteristics of Daxing Airport "rail to air transfer" user demand and service design, related design elements were analyzed from three service 
Table6. Expansion table of design elements

\begin{tabular}{|c|c|c|c|c|c|c|}
\hline $\begin{array}{c}\text { Primary } \\
\text { design }\end{array}$ & \multicolumn{6}{|c|}{ Secondary design elements } \\
\hline $\begin{array}{c}\text { Y1 } \\
\text { Physical } \\
\text { element }\end{array}$ & $\begin{array}{l}\text { Y11 } \\
\text { Check-in } \\
\text { counter } \\
\text { of } \\
\text { subway } \\
\text { station } \\
\text { hall } \\
\end{array}$ & $\begin{array}{l}\text { Y12 Seats in } \\
\text { departure } \\
\text { lounge and } \\
\text { floor area }\end{array}$ & $\begin{array}{c}\text { Y13 } \\
\text { Commercial } \\
\text { stores in } \\
\text { airside } \\
\text { concourse }\end{array}$ & $\begin{array}{l}\text { Y14 Electric } \\
\text { footpath in } \\
\text { transfer } \\
\text { subway } \\
\text { station }\end{array}$ & $\begin{array}{l}\text { Y15 Signage } \\
\text { system } \\
\text { information }\end{array}$ & $\begin{array}{c}\text { Y16 } \\
\text { Location } \\
\text { information } \\
\text { and } \\
\text { identification } \\
\text { of check-in } \\
\text { counter }\end{array}$ \\
\hline $\begin{array}{c}\text { Y2 } \\
\text { Artificial } \\
\text { element }\end{array}$ & \multicolumn{3}{|c|}{$\begin{array}{c}\text { Y21 Intelligent equipment for } \\
\text { passengers under assistance of airport } \\
\text { staff }\end{array}$} & \multicolumn{3}{|c|}{$\begin{array}{l}\text { Y22 Boarding tidal inlet for artificial } \\
\text { verification3 }\end{array}$} \\
\hline $\begin{array}{c}\text { Y3 } \\
\text { Digital } \\
\text { element }\end{array}$ & \multicolumn{2}{|c|}{$\begin{array}{l}\text { Y31 Information display } \\
\text { screen }\end{array}$} & \multicolumn{2}{|c|}{$\begin{array}{l}\text { Y32 Self-help system } \\
\text { interface design }\end{array}$} & \multicolumn{2}{|c|}{$\begin{array}{l}\text { Y33 Efficiency of self-help } \\
\text { baggage check-in facilities }\end{array}$} \\
\hline
\end{tabular}

The importance degrees of all design elements were calculated according to the correlation matrix, the

basement of HOQ was constructed, thus completing the construction of HOQ as shown in Fig 4.

\begin{tabular}{|c|c|c|c|c|c|c|c|c|c|c|c|c|c|}
\hline \multirow{3}{*}{\multicolumn{2}{|c|}{$\begin{array}{l}\text { Design } \\
\text { Elements } \\
\text { User } \\
\text { Demand }\end{array}$}} & \multicolumn{6}{|c|}{ Y1 Physical element } & \multicolumn{2}{|c|}{ Y2 $\begin{array}{c}\text { Artificial } \\
\text { element }\end{array}$} & \multicolumn{3}{|c|}{ Y3 Digital element } & \multirow{3}{*}{$\begin{array}{c}\text { User } \\
\text { Demand } \\
\text { Weight }\end{array}$} \\
\hline & & Y11 & Y12 & Y13 & Y14 & Y15 & Y16 & Y21 & Y22 & Y31 & Y32 & Y33 & \\
\hline & & + & + & - & + & - & + & + & + & + & - & + & \\
\hline \multirow{4}{*}{ 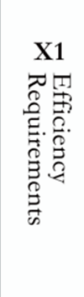 } & X11 & & & & & & & & & & & & 0.1998 \\
\hline & X12 & & & & & & & & & & & & 0.1022 \\
\hline & X13 & & & & & & & & & & & & 0.2651 \\
\hline & X14 & & & & & & & & & & & & 0.0561 \\
\hline \multirow{3}{*}{ 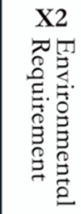 } & $\mathrm{X} 21$ & & & & & & & & & & & & 0.1302 \\
\hline & X22 & & & & & & & & & & & & 0.0829 \\
\hline & $\mathrm{X} 23$ & & & & & & & & & & & & 0.0264 \\
\hline \multirow{3}{*}{ 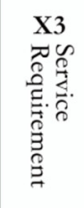 } & X31 & & & & & & & & & & & & 0.0740 \\
\hline & $\mathrm{X} 32$ & & & & & & & & & & & & 0.0225 \\
\hline & X33 & & & & & & & & & & & & 0.0408 \\
\hline \multicolumn{2}{|c|}{$\begin{array}{c}\text { DESIGN } \\
\text { FACTOR WEIGHT }\end{array}$} & 0.1486 & 0.0347 & 0.0280 & 0.0450 & 0.1804 & 0.0828 & 0.1283 & 0.0807 & 0.0321 & 0.1794 & 0.0600 & \\
\hline
\end{tabular}

Note: the correlation was strong, medium, weak and there were no four categories. The score is 5,3,1,0; The symbols are $\bigcirc, \bigcirc$ and space

Figure 4. Quality room for Rail to Air transfer mode of Daxing Airport

Physical contact points: The following can be obtained

\subsection{Suggestions for optimizing Daxing Airport Rail to Air transfer mode}

Following an analysis by combining weights of design elements, suggestions for optimizing physical, artificial and digital contact points of Daxing Airport "rail to air transfer" service were proposed. through the weight relation of physical elements, namely Y15 $>$ Y11 $>16>$ Y12 $>$ Y13 $>$ Y14. (1) Simplify the guidance system information and provide larger spreading area for pointing identifications and critical location information. (2) Increase check-in counters in subway station hall, which can shorten the time spent by passengers to experience transfer carrying baggage by a large margin, as 
passengers are already shunted in early service stage. (3) Provide location information of check-in counter and enlarge its identifications. This can solve passenger detouring problem and improve check-in efficiency. (4) Increase seats in the departure lounge and enlarge its area according to the characteristic of Daxing Airport, namely co-existence of departing passengers and arriving passengers, so as to improve the comfort of waiting passengers and disperse the crowd on aisles. (5) Re-plan commercial stores or their decorations in airside concourse while not influencing passengers to seek for access to departure gate and discriminate identifications. (6) Increase the construction of electric footpaths on the longdistance aisle in front of Daxing Airport subway station, so as to shorten walking distance of transfer passengers.

Artificial contact point: According to the weight relation of artificial elements, namely Y21 $>$ Y 22 , the following can be obtained: (1) increase intelligent equipment for passengers under assistance of airport staff, improve use efficiency and experience of digital equipment among some passengers, and meanwhile, reduce congestion degree at self-help check-in site and save total time consumed by self-help check-in. (2) Increase the construction of tidal inlets for artificial verification at boarding gate and relieve congestion of departing and arriving passengers.

Digital contact points: based on weight sorting of digital elements - Y32>Y33>Y31, (1) simplify interface design of self-help check-in equipment, information entry and navigation and positioning equipment, lower passenger use threshold and improve passenger check-in and transfer efficiency. (2) The current self-help baggage check-in equipment has certain requirements for locating place and orientation of baggage with low error-tolerant rate. To solve this problem, it is necessary to elevate identification requirements for self-help baggage check-in facilities and improve error-tolerant rate of passengers for this equipment, so as to shorten check-in time and mitigate personnel retention problem. (3) Upgrade the existing small-type information release display screen or enlarge its size, display transfer information to transfer passengers, and reduce artificial inquiry pressure.

\section{Optimization design of Daxing Airport Rail to Air transfer mode service blueprint}

\subsection{Drawing of service optimization blueprint}

A service blueprint is needed in service design to improve and master the quality of personnel, environment and system, etc.[10]. The suggestions for optimizing Daxing Airport "rail to air transfer" service were introduced into the drawing of service blueprint, passenger behavior, staff behavior and support system were integrated and intuitively displayed by the service blueprint, aiming to diagnose and improve the service process and seek for service gaps needing urgent solutions, so as to realize more coherent, orderly and highly efficient service flow, realize optimization and matching of user demand and service system and improve user transfer experience as shown in Fig 5.

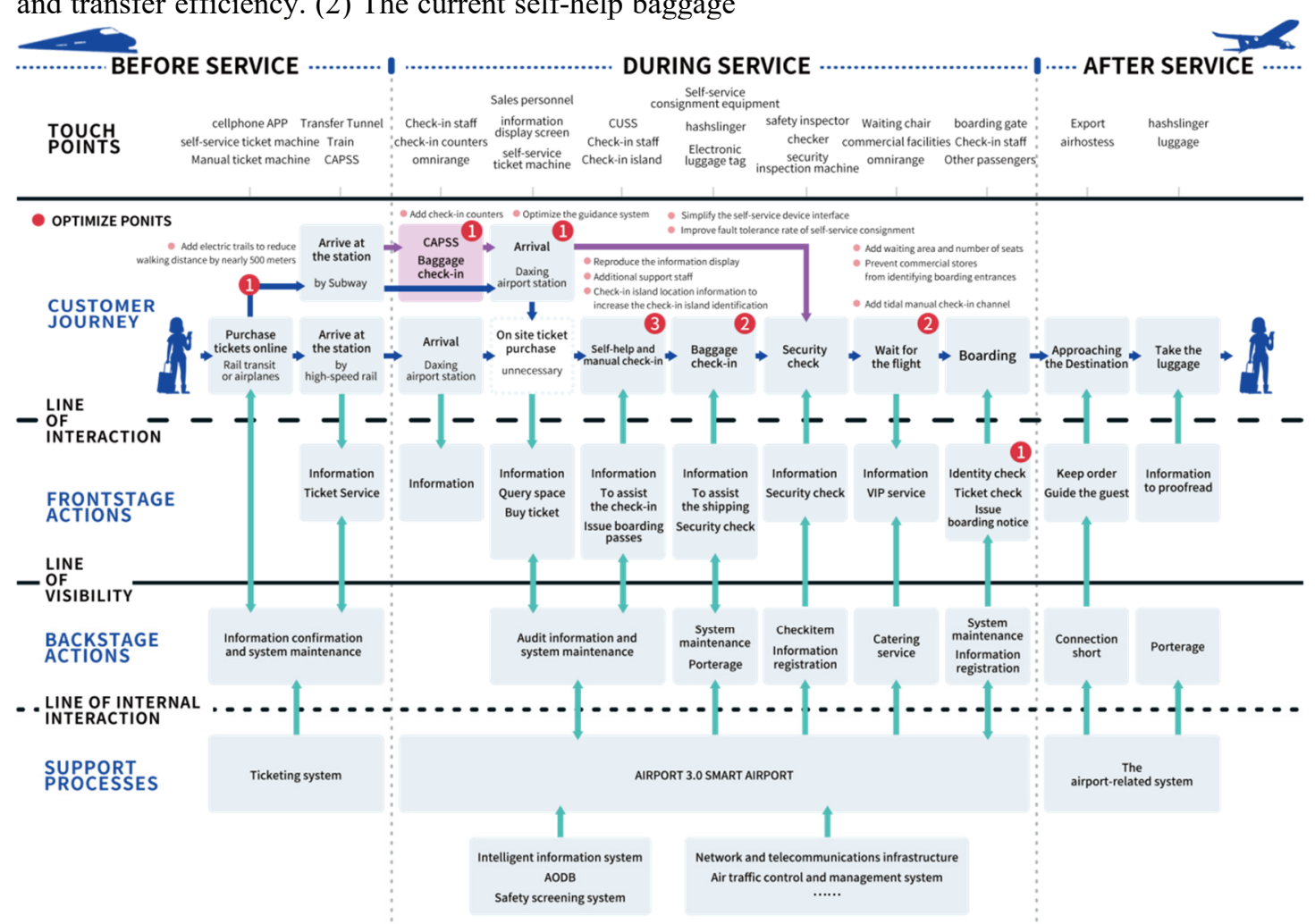

Figure 5. Service Optimization blueprint for Rail to Air transfer mode

The service optimization blueprint for "rail to air transfer" mode of Daxing Airport includes the following elements. (1) Contact point: including tangible facilities and personnel services provided by Daxing Airport passenger terminal to transfer passengers, e. g. check-in counter, navigation system, self-help equipment, etc. (2) 
Passenger behavior: covering the whole behavioral process of passengers before, in middle and after enjoying "rail to air transfer" service. (3) Front-desk and backstage staff behavior: displaying service contents and service behaviors of visible and invisible staffs providing passengers with transfer service. (4) Supporting process: indicating related systems providing technical and HR support for front-desk and backstage services, e. g. ticketing system, intelligent information system, airport operation database, etc. Regional division is carried out among the abovementioned elements through three parallel boundaries: boundary between contact point and passenger behavior, interaction line and visible line. When any longitudinal line crosses the boundary, it can be observed that transfer passengers initiatively or passively serve and contact staffs at the hub according to the direction of arrow.

\subsection{Service analysis after mode optimization}

It can be seen from the optimized blueprint that in Daxing Airport "rail to air transfer" service, basic demand factors like transfer connection, safety guarantee, intelligent level of facilities and carrying capacity of transfer carrier do not exert any significant negative effect on passenger transfer experience any longer. However, from the quantity and distribution of optimization points in the blueprint, as Daxing Airport hub has been constructed for not a long time, it still has large improvement space in aspects of signage system, identification information, passenger utilization efficiency of intelligent system, and passenger waiting experience, where upgrading signage system, improving passenger utilization efficiency of intelligent system and optimizing organization of passenger flow account for the highest proportion in weights of user demand and technological element, thus becoming important factors influencing passenger transfer experience.

\subsubsection{Service analysis after mode optimization}

The signage system setting is more reasonable and conspicuous. After guidance information is clearer, it can effectively reduce detouring distance during passenger transfer. Surplus location information in secondary signages above escalator and at corner, so as to improve user recognition degree and recognition time for signage information and improve check-in and traffic efficiency.

\subsubsection{Improve passenger utilization efficiency of intelligent system}

Based on realization of digital intelligent services in the whole transfer flow, timely assisting transfer users with low acceptance can save information entry and check-in time. Functional propaganda and interface introduction of intelligent check-in equipment in "pre-service" stage can shorten time cost of misoperation, relieve check-in personnel retention problem and lower the flow pressure during artificial check-in.

\subsubsection{Optimize organization of passenger flow}

In consideration of humanization, walking aid facilities can be constructed in long-distance corridor on transfer midway from Caofang Station to Daxing Airport to relieve transfer burden of special passengers; actively guiding subway transfer passengers to check in and conduct baggage check-in in subway station hall can save passenger walking time carrying baggage and lower the pressure of passenger flow checking in in the terminal; As departing and arriving passengers in Daxing Airport are both dispersed at departure gate, constructing additional accesses to boarding gate for artificial verification according to flow quantity of departing and arriving passengers in each period can relieve congestion degree in transfer channel. Self-help baggage check-in facilities can be upgraded to improve scanning success rate of suitcases placed at different angles and effectively reduce personnel retention at baggage check-in position.

\section{Conclusion}

Adhering to the "people-oriented" construction concept, Daxing Airport keeps up with world top-class passenger traffic quality and service quality. The service level, as one of important functions of Daxing Airport Comprehensive Hub, has a direct bearing on passenger travel quality and user experience. As for how to improve "rail to air transfer" user experience, QFD and service design method were combined in this study. Starting from passenger demand, demand weights were determined via AHP method, and HOQ was constructed to realize demand transformation. In the end, the optimization suggestions were summarized according to the obtained weights, the service optimization blueprint was drawn, and the visualized improvement of Daxing Airport "rail to air transfer" service in current period was completed. The user demands in Daxing Airport "rail to air transfer" service in the aspects of signage system, improvement of passenger utilization efficiency of intelligent system and organization of passenger flow were obtained through this method. With strong operability and applicability, this study has provided new improvement strategy and method for related transfer modes in other comprehensive passenger transportation hubs.

\section{Acknowledgments}

Funded Program. 2019-2020 Development Research Centre of Beijing New Modern Industrial Area Open Project Funding.

\section{Refrences:}

1. Chen Hong-bo, Cao Zhe-yi, Wang Tao, et al. Research on the comprehensive traffic improvement of Beijing airport under the background of two events in one city [J]. Civil aviation management, 2019, 30 (02): 67-71. 
2. Nie Ting-ting, Zheng Wei-qing, Sun Yang, et a. Evaluation method of passenger transfer service level in comprehensive passenger terminal [J]. Transportation research, 204, 5 (06) : 43-49.

3. Lai-Kow Chan, Ming-Lu Wu. Quality function deployment: A literature review[J]. European Journal of Operational Research, 2002, 143(3). Donald. A. Norman. Design Psychology 3 [M]. Beijing: CITIC Press, 2nd Edition, June 2015.

4. Duan Li-ming, Huang Huan. Integration method and application of QFD and Kano model [J]. Journal of chongqing university, 2008 (05) : 515519.

5. Xin Xiang-yang, Cao Jian-zhong. Service design driving public affairs management and organizational innovation [J]. Design, 2014 (05) : 124-128.

6. Chen Jia-jia. Service Design [M]. Lianyungang:Jiangsu Phoenix Art, 2016.

7. Wang Zhong-tuo. System engineering [M]. Beijing:Peking University press, 2015.

8. Guo Xi-ya, Nie Xiao-fen, Wang Jia-hao. Research on hardware tool design based on QFD [J]. Mechanical design, 209, 36 (12) : 122-126.

9. Deng Cheng-lian. Touching service contact point [J]. Decoration, 2010 (06) : 13-17.

10. Hu Xiao-juan. Design and application of railway passenger station service blueprint [J]. Railway transportation and economy, 209, 41 (06) : 48-52. 